\title{
Just-Released JCR Impact Factor Shows Strong and Steady Increase for ABC Cardiol - 1.679 - A New Historical Record
}

\section{Carlos E. Rochitte* ${ }^{*}$}

Instituto do Coração - Incor, São Paulo, SP - Brazil

* Editor-Chefe da ABC Cardiol - Arquivos Brasileiros de Cardiologia

Dear friends from the Cardiology and Cardiovascular scientific community in Brazil and abroad, please allow me this short editorial with extraordinary news on the ABC Cardiol Journal, accompanied by data, of course.

We are delighted to announce that our peer-reviewed journal of The Brazilian Society of Cardiology, the ABC Cardiol (Arquivos Brasileiros de Cardiologia), has seen significant increase in its impact factor rating in the latest Journal of Citation Reports (JCR) release. Our impact factor went up from 1.318, released last year (2017 rate) to 1.679 this year (2018 rate), a 27\% increase in one year and the highest impact factor ever for ABC Cardiol.

We can see a clear and steep increase of the impact factor in Figure 1, ${ }^{1}$ breaking the barrier of 1,5 impact factor. Articles published in the $\mathrm{ABC}$ Cardiol received a staggering 3000 citations in 2018 alone (Figure 2). ${ }^{1}$ Another barrier that was broken by $\mathrm{ABC}$ Cardiol this year is the third Quartile. We are now ranked at the Q3 of all 136 Cardiac and Cardiovascular System journals in the World (Table 1). ${ }^{1}$ ABC Cardiol galvanized his position of the highest ranked Journal in Cardiology and Cardiovascular Science in Latin America, position that was reached and maintained since 2014 (see Table 2). ${ }^{2}$

One important aspect of the progression of our JCR impact factor is depicted in the Table $3 .^{1}$ While in the same period of 2017 to 2018, most of Cardiology and Cardiovascular Science and Medical Journals in Brazil only maintained or even decreased their impact factor, ABC Cardiol steadily increased in a significantly amount its impact factor, only followed by a basic research journal. So, in our scientific community in Latin America ABC Cardiol has established itself as the main reference journal for Cardiology and Cardiovascular Science.

The rise in impact factor means that our research community is recognizing the articles being accepted and

\section{Keywords}

Bibliometrics; Journal Impact Factor; Periosicals as Topic; Scimago.

Mailing Address: Carlos E. Rochitte •

Av. Dr. Enéas de Carvalho Aguiar 44 - Andar AB - Ressonância \& Tomografia

- Cerqueira César - 05403-000 - São Paulo, SP - Brazil

E-mail: rochitte@cardiol.br,rochitte@incor.usp.br

DOI: $10.5935 / a b c .20190135$ published in ABC Cardiol journal as relevant and impactful science. This accomplishment fulfills ABC Cardiol mission that is to promote new knowledge and publish the latest research, emerging technologies and breakthrough advances in Cardiology and cardiac diseases.

ABC Cardiol journal is free and open access journal that can be viewed, downloaded and accessed by mobile app from anywhere in the World. The readers can interact with editorial board members and authors through social media (Facebook, Tweeter, Instagram, etc) and through movie posts in our newly re-designed web-portal.

This important step on the ABC Cardiol progression toward a higher scientific rank was only possible by a continuous editorial policy that started several years back with Dr. Luis Felipe Moreira, former Editor-in-Chief, to whom we are deeply grateful. Our international and talented associate editors' team, dedicated editorial board and reviewers are by far the main reason that led $\mathrm{ABC}$ Cardiol to his current position. The strong support from our Brazilian Society of Cardiology board of directors to the $\mathrm{ABC}$ Cardiol has been crucial to achieve our goals of increasing our impact and presence in the scientific community. Our dedicated team of editorial assistants that does not measure the efforts to achieve timely and high quality publication is of paramount importance to our ABC Cardiol journal operation. For me as editor-in-chief, running $A B C$ Cardiol and working together with this great team of professionals in our office in São Paulo and in Rio de Janeiro has been a blessing. Thank you so much for this delightful experience.

Our editorial policy is focused in the scientific quality of submitted manuscripts and the novelty they bring to the field. We welcome new and revolutionary ideas brought to light by rigorous scientific method in well-written manuscripts. Our main language is English, but we accept and publish all articles bilingually, English and Portuguese.

We have editorial comments for all published original articles, which place the new science in context with the specific research field. ABC Cardiol is also the home of all clinical guidelines, statements and expert consensus endorsed by the Brazilian Society of Cardiology. All guidelines are now published in Portuguese and English and within the body of the Journal. With these recent improvements in our editorial policy and continuous support from our scientific community and post-graduation programs in Brazil we hope we can break another impact factor barrier next year. Thank you all very much. 


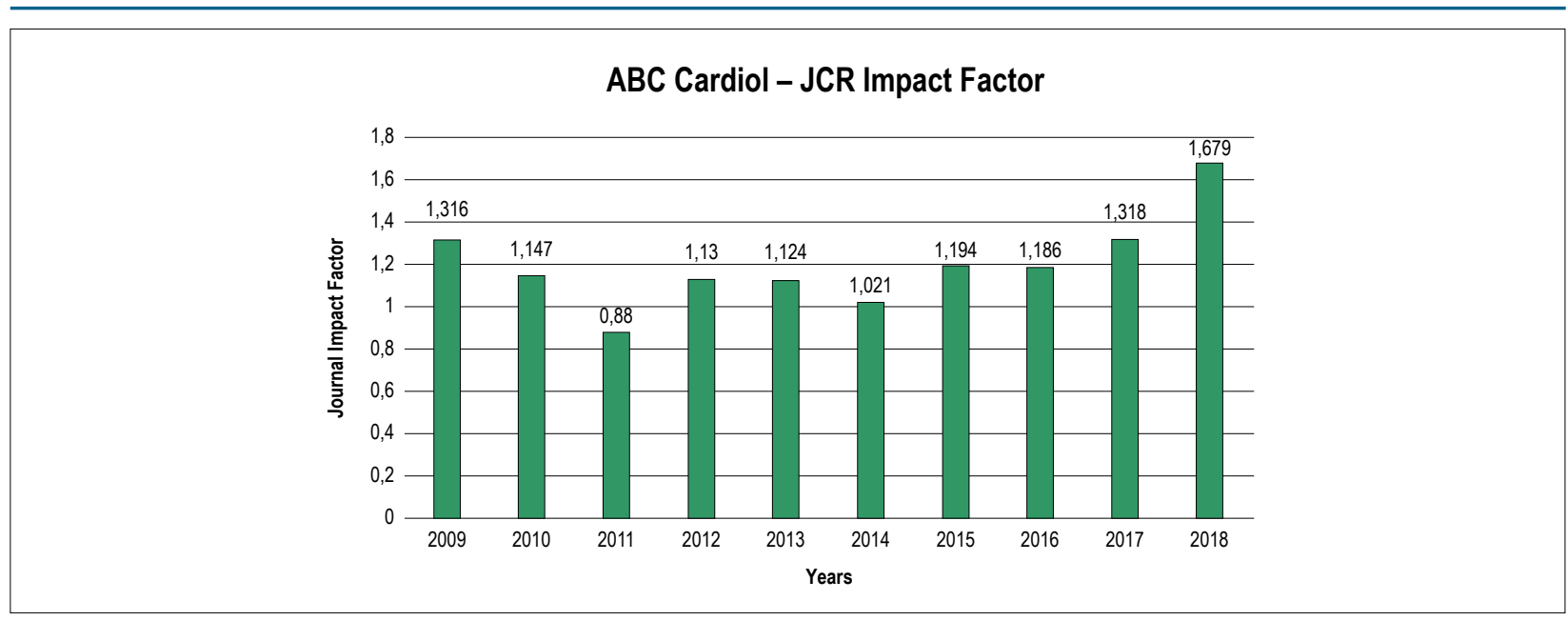

Figure 1 - ABC Cardiol JCR Impact Factor from 2009 to 2018. Source: JCR

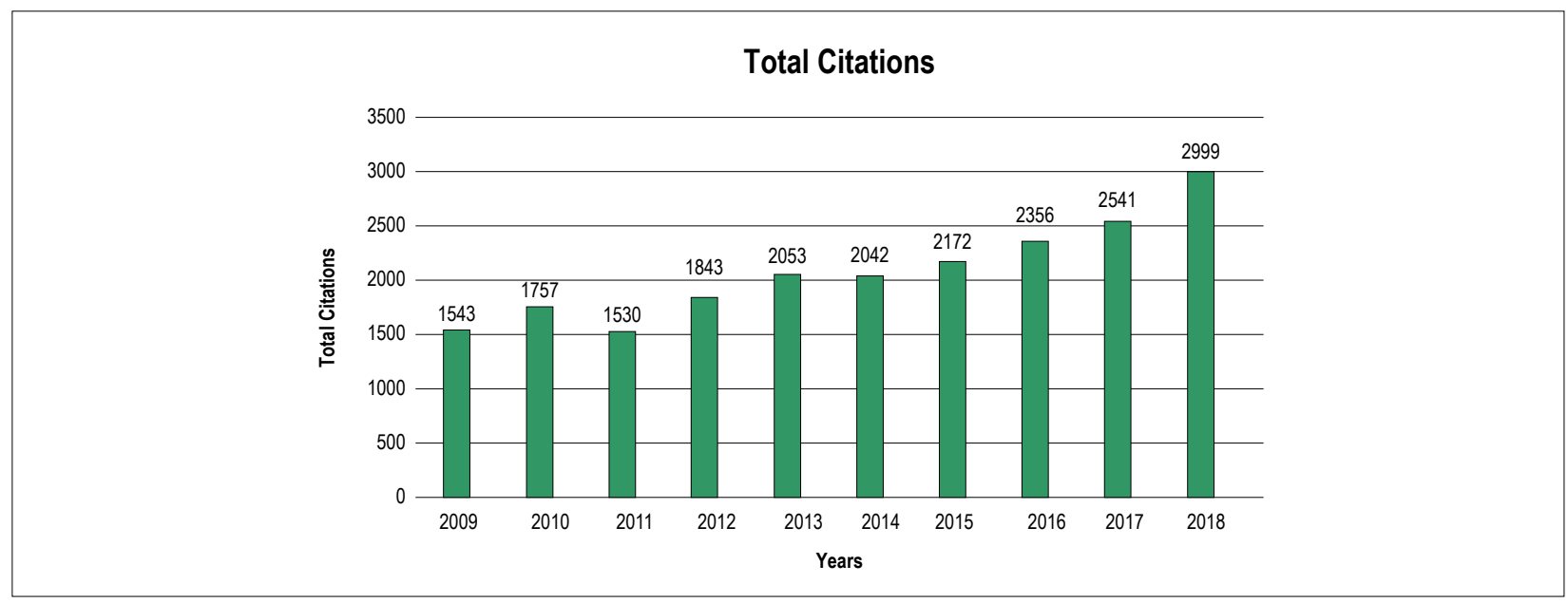

Figure 2 - ABC Cardiol Total Citations per Year. Source JCR ${ }^{1}$

Table 1 - ABC Cardiol Quartiles Rank from 2009 to 2018. Source JCR ${ }^{1}$

\begin{tabular}{lccc}
\hline \multirow{2}{*}{ JCR year } & \multicolumn{3}{c}{ Cardiac and Cardiovascualr systems } \\
\cline { 2 - 4 } & Rank & Quartile & JIF Percentile \\
\hline 2018 & $98 / 136$ & Q3 & 23.309 \\
2017 & $106 / 128$ & Q4 & 17.578 \\
2016 & $107 / 126$ & Q4 & 15.476 \\
2015 & $97 / 124$ & Q4 & 22.177 \\
2014 & $100 / 123$ & Q4 & 19.106 \\
2013 & $96 / 125$ & Q4 & 23.600 \\
2012 & $91 / 124$ & Q3 & 27.016 \\
2011 & $98 / 117$ & Q4 & 16.667 \\
2010 & $87 / 114$ & Q4 & 24.123 \\
2009 & $63 / 95$ & Q3 & 34.211 \\
\hline
\end{tabular}




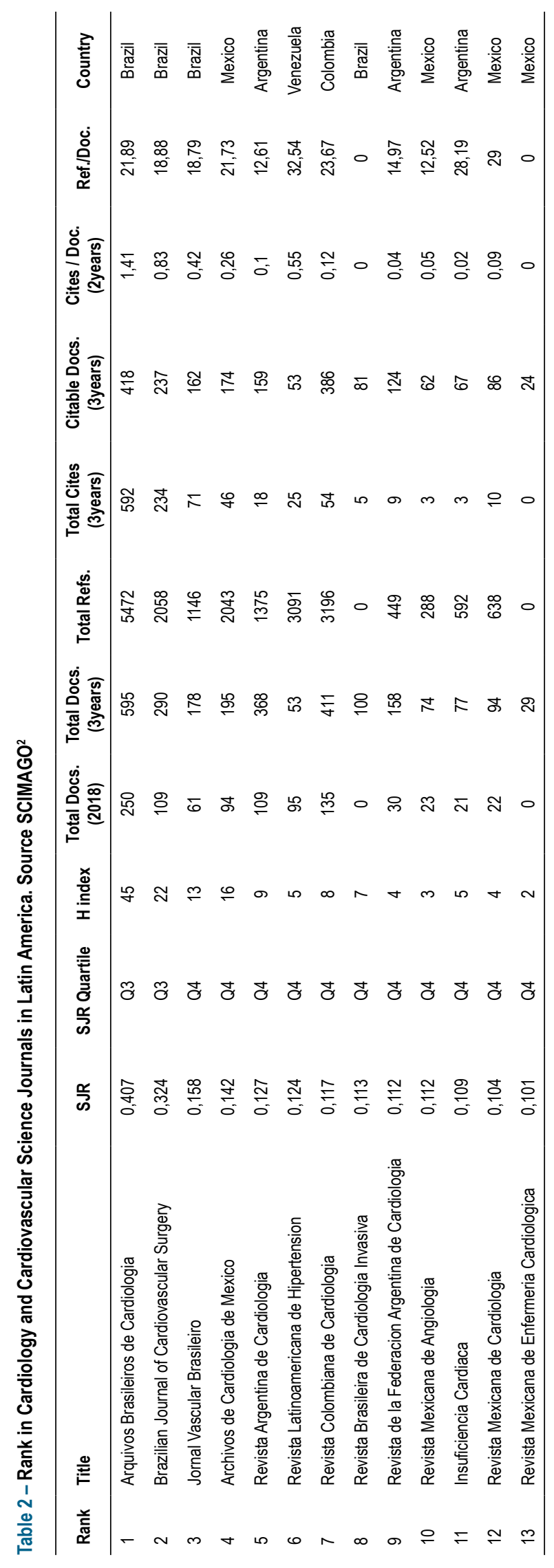


Editorial

Table 3 - JCR impact factor for 2017 and 2018 for Brazilian Journals (Cardiovascular Field, Medicine and Basic Research). Source JCR

\begin{tabular}{lcc}
\hline Journal & Impact Factor 2017 & Impact Factor 2018 \\
\hline Arquivos Brasileiros de Cardiologia & 1,318 & 1,679 \\
Brazilian Journal of Cardiovascular Surgery & 0,805 & 1,796 \\
Brazilian Journal of Medical and Biological Research & 1,492 \\
Clinics & 1,245 & 1,127 \\
Memorias do Instituto Oswaldo Cruz & 2,833 \\
Revista da Associacao Medica Brasileira & 0,736 \\
Sao Paulo Medical Journal & 1,063 \\
\hline
\end{tabular}

\section{References}

1. Journal Citation Reports. Clarivate Analytics. [Cited in 2019 June]. Available from: https://jcr-clarivate.ez67.periodicos.capes.gov. brJCRJournalHomeAction.action
2. Scimago Journal \& Country Rank. Scimago Lab.[Cited in 2019 June 29]. Available from: https.//www.scimagojr.com 